\title{
Introduction: Local Democratic Governance, Poverty Reduction and Inequality: The Hybrid Character of Public Action
}

\author{
Peter K. Spink and Nina J. Best*
}

\begin{abstract}
It has largely been assumed that as societies get better at being broader and more open (decentralisation, local government, participation and governance), so services tend to improve and things will get better for those in situations of poverty. In testing this assumption, the LogoLink network has drawn on studies of innovative experiences by members of its partner organisations. The emphasis of the joint project was on the local actors and the social processes involved. The results show how effective action and impact requires not only community-based organisations, social movements and NGO networks, but also public sector actors who can make links between the institutional environment, the public sector and communities. Recognising this hybrid character of public action has been a key conclusion from the studies.
\end{abstract}

Nelson and Dorsey (2008) have recently pointed to the way in which two previously independent debates in international circles are now coming closer together: that of development, with its concerns about better living conditions, poverty reduction, strengthening democracy, economic and social progress, and that of human rights, focused on violations of civil and political rights and the protection of refugees. Totally separate during the 1950s-1980s, moving along in parallel in different issue networks and communities with different publications, conferences, organisations or departments, they are increasingly found together for both substantive and tactical reasons. The same can perhaps be said for the themes that stimulated the research programme, whose results are being presented in this $I D S$ Bulletin: decentralisation, local government, participation and governance on the one hand and poverty and inequality on the other.

Linked to the broader discussion of democracy, empowerment, representation, service provision and social and economic inclusion, it has largely been assumed that as societies get better at being more broader and open (decentralisation, local government, participation and governance) so services tend to improve and things will get better for those in situations of poverty. However, in terms of the literature, the two themes have very much followed their own routes and it is only now, linked perhaps by concerns about accountability and transparency, that the two have - as it were - bumped into each other.

The current study is a continuation of previous work by LogoLink, a network of intermediary and activist organisations ${ }^{1}$ that seeks to advance understanding of the changing roles of social actors and their strategies in promoting local democratic environments that contribute to reducing poverty and exclusion. It draws on studies specially commissioned by partner organisations through their own regional and local networks to look at two central dimensions: key actors, processes/strategies and the relationship between them. What are the roles, relationships and changes taking place among key actors such as political parties, civil society organisations, local communities, nongovernmental organisations (NGOs), local governments, social movements, central 
governments, donors and the private sector? Cases were chosen from Latin America, Southern and East Africa and South, East and South-east Asia and in settings where LogoLink partners have developed a variety of interventions such as citizenship education, voter literacy, participatory planning, social control, budget monitoring and party building, among others. The primary questions driving this collective effort have been:

What are innovative experiences where changes in local democratic governance have enhanced delivery, effectiveness and/or inclusiveness of initiatives to fight poverty and inequalities and vice versa? To what extent have different actors played a key role in the processes and strategies that enabled democratic local governance to affect poverty and inequalities and, inversely, to what extent have the processes and different strategies impacted the actors, their relationships and local governance arrangements?

At a more global level, the rationale for this research draws on discussions with the Ford Foundation and with other donors and international actors about the impacts of participation on poverty reduction and social inclusion and where there is a general consensus that top-down development policymaking and implementation has fallen short of addressing the needs of the poor. In this context, citizen participation, once considered controversial, has been incorporated into mainstream development theory and practice and is being applied, to different extents, by virtually all development agencies. However, the extent to which citizens participate and the nature of their participation varies widely, from punctual and instrumental consultations to more meaningful citizen participation in institutionalised spaces. However, despite these advances, the questions of impact remain.

In Latin America for instance, there have been two decades of civil society mobilisation to participate in policy planning and monitoring and the opening up of new institutional spaces for participation triggers increasing demands for participation to deliver results that go beyond empowerment and deepening political democracy. More and more, participation is explicitly asked to deliver results in terms of poverty reduction and social justice. At the same time, some have argued that by mainstreaming participation into development approaches, participation has lost much of its political and empowering content.

Hence, questions emerge about the changes being brought about in the relationship between social and political actors. Communities are not harmonious entities but rather they are ridden by complexity and conflict, and local power systems and patronage can reinforce inequalities in the social structure and prevent certain groups, often women, ethnic and religious minorities and the poorest of the poor, from participating on equal grounds and voicing their concerns. In some parts of the world, traditional political parties are undergoing unprecedented fragmentation. In parallel, in many southern countries, civil society groups constitute a major segment of the forces for reform, pressuring for new ways of doing politics. Beyond strategies for people's empowerment, intermediary actors have also engaged in different forms of interaction with local authorities and political actors. In some cases, they have been challenged to enter the political arena to accumulate power through parties and elections, especially at the local level. What have been the implications for these actors? What have they learned and how have their strategies and/or identities been altered in this process? To what extent has this altered traditional power relations and patronage? These are difficult themes and certainly merit separate studies in their own right but, nevertheless they are questions that can be expected to be around when looking at the pushes and pulls of everyday action.

In the same way, while is was hoped that the research would pay specific attention to cases where strong and meaningful citizen participation has played a key role in building local democratic governance environments, it was also expected that they would be able to consider the changes taking place in the broader governance context that, combined, have had some impact on poverty and exclusion, such as the relationship between different governance levels, institutional frameworks, decentralisation processes and others.

In the preliminary discussions for the research brief, the decision was made to focus on these 
questions at the level of local governance, understood as municipal, village, district and sub-district levels of governance, and at the new roles and responsibilities taken up by a series of social and political actors. What are the roles, relationships and changes undergone by key actors like political parties, civil society organisations, local communities, NGOs, local governments, social movements, central governments but also donors and the private sector? What are the changes that have been brought about in the relationships between these actors and how have power relations been altered? To what extent do these new environments create better potential for fighting poverty, exclusion and inequalities? What are the circumstances and enabling processes at play, such as institutional frameworks, participation mechanisms, central-local government relations, social and development policies, decentralisation processes, among others?

The selection of cases followed a two-step process. First, the different partner organisations of LogoLink met together to discuss the general thrust of the work and set out key criteria. Cases would look at citizen participation as a central element in promoting local democratic governance but would also consider other dimensions like the relationship between different governance levels, institutional frameworks and decentralisation processes, among others. The choice of policy or programme was left open to be chosen for its relevance to the country's local governance and development contexts. These could range from housing, maternal health, education, access to credit, sanitation, to policies that foster local economic development, cash transfer programmes, policies and programmes targeting youth, women, ethnic minorities and others. The major criterion was the policy/programme's contribution to improving the lives of poor and excluded groups. Where possible, the policy or programme studied should also have been implemented in the last four years in order to avoid the trap of selecting cases that have been over-studied, or when longer should allow for new material for critical assessment. Following this, a short list of cases was drawn up and discussed by the partner organisations before settling on the final list. Key here was to avoid comparative simplifications and accept the complexity of the different cases, rooted in specific circumstances. The question for the research coordinators was that of dialogue could the cases talk to each other? Would they raise questions that collectively might move the discussion forward?

Case studies were selected from Brazil, China, India, Mexico, the Philippines, Peru, South Africa and Uganda. The Brazilian case study looks at the history of the fights around urban housing policy in Diadema, a working class municipality in the Greater São Paulo region. In China, the case study looks at a network that grew up to support rural migrant workers in urban Chengdu, capital of Sichuan Province. In India, PRIA (Society for Participatory Research in Asia) worked with colleagues at Nagaland University to look at empowerment, service delivery and community organisational outcomes of the Communitisation of development programmes in Nagaland. In Mexico, the case study looks at interventions to combat violence against women in the Sierra of Zongolica, with a focus on gender and ethnicity. The Philippines case study describes and discusses the Institute for Popular Democracy's (IPD) strategies for the co-production and co-financing of local service delivery. The Peruvian case looks at participation in pro-poor interventions (service delivery, participatory budgeting, and others) in Anta, in the Andean department of Cusco. In South Africa, the case follows a Citizen Voice Project intervention using scorecards in rural water service delivery. Finally, the research in Uganda assesses local strategies - including those of DENIVA (Development Network of Indigenous Voluntary Associations) itself - in promoting democracy and rights of the urban poor, with a special emphasis on the delivery of health services in Jinja Municipality.

A research brief was drawn up for the case studies to ensure a certain degree of cohesion, yet at the same time allowing each study to follow its own path. In general, this involved gathering policy documents and other printed material such as evaluations, semi-structured interviews with key civil society organisations, other social actors engaged in the process, political actors (local authorities, civil servants, national authorities, political parties) and research establishments. The emphasis throughout was on actors, actions and processes, attempting where possible - and within the inevitable constraints of very small research 
budgets - to develop an action-centred view of the different cases.

\section{The case discussions}

All the cases corresponded to the high expectations that the LogoLink team had created in the run up to the follow-up workshop to discuss the preliminary versions of the case studies. They were clearly at the cutting edge of a number of serious questions in each country. One of the more common criticisms levelled against case research is that because of its qualitative nature, it is not able to pick up broader trends, which require other types of methods in order to be effective. The results of the Bellagio workshop where the case teams discussed the studies showed that, on the contrary, providing cases are well contextualised and dynamic descriptions made at the level of actors and processes, it is indeed possible to pick up certain aspects of trends and tendencies. Individual cases are rarely isolated single events and much more often a product of a chain of events, conversations and concerns that provide a mid-range horizon, both organisationally and territorially, within which action is taking place.

Many of those present at the case discussion workshop, given the extensive citizen and grass roots activist history of the LogoLink network, probably started with a strong bias towards the importance of civil society organisations as opposed to government as the engines of change. All the cases had involved research very close to the ground where action was taking place and in many cases, a close involvement in action research. But what the cases showed, over and over again in many different ways, is that equally important as community-based organisations, social movements and NGO networks, are the key actors in the public sector who are able to open doors or build bridges between the institutional environment, the public sector and the day-to-day of community and collective life.

It was also very interesting to see how ideas travel, such as co-management processes and participatory budgeting, but also to see how, at times, it is necessary to draw a very clear line if not also a confrontational line - between state and civil society. New questions were also placed on the table, such as explicit citizen co-financing activities and the need to recognise the positive role that government-sponsored NGOs can also play in certain circumstances.
The importance of intermediary actors was another key point, especially in relation to settings in which formal representation is not clear. However, here there is still much doubt as to whether the consequences of mediation are necessarily positive for the different sides involved. Seeing intermediary organisations as 'open bridge' organisations that support linkage but do not seek to become reference organisations in their own right, is perhaps a helpful metaphor. Equally, many of the countries in which the studies were located have enabling legislation for citizen participation. However, it proved important to make a distinction between government-sponsored or 'invited' spaces and citizen-stimulated and 'invented' spaces. Here there is much to be learned about how to design more open mechanisms that can effectively empower rather than enable citizen voice.

A great concern of all present was that - following the lines of the original proposal - the path to meaningful and significant impacts on poverty and inequality is still a very difficult one and needs to be seen much more as a field of possibilities which will need to be built up in different manners in different circumstances. The best approach, the simple bullet points of development templates, the obviousness of logical framework analyses or the guides to replication and 'scale', somehow do not do justice to the very real challenges and partial successes of street and field level action, or to the complexity of midrange inter-organisational settings which will be picked up in more detail in the closing article. For this reason, when looking for a title to head this presentation and discussion of the case studies we were drawn to bring together two notions: of public action and of hybrid arenas.

\section{The hybrid character of public action}

Public action is an expression that crept into the development discussion almost as an obvious one; one of those phrases that seemed so naturally part of public affairs, as indeed it had been since at least the transition to modernity in medieval Europe. Its presence can be found in the earlier writings of Adam Ferguson (1767: 59) on civil society in extolling that if the public good be the principle object with individuals, it is likewise true, that the happiness of individuals is the great end of civil society: for in what sense can the public enjoy any good, if its members, considered apart, be unhappy?' In a not so 
dissimilar manner, Hirschman (1982: 6) in his text on private interests and public action would say 'public action, action in the public interest, striving for the public happiness - these all refer to action in the political realm, to involvement of the citizen in civic or community affairs'.

In an earlier publication of his now famous Italian study, Putnam (1988) set his discussion in the arena of civic culture, using both de Toqueville on 'mores', an earlier kind of civic disposition, and Almond and Verba's (1963) classic comparative study of civic culture in five countries. Their focus was on the UK, where they saw the story of the civic culture written large but would also recognise that the USA, the Scandinavian countries, Holland and Switzerland appeared to have worked out their own version 'of a political culture and a practice of accommodation and compromise'. Looked at in hindsight, as Ehrenberg (1999) has well commented, Almond and Verba's arguments show considerable aversion to conflict and their view of British history was considerably pastoral. There is no place for the Chartists, the Levelers, Cromwell, strikes and massacres among their observations on consensus and compromise. 'Like many social scientists of the period, Almond and Verba shared Truman's worries that high levels of political activity might be politically destabilising. This is why their composite "civic culture" combined participation with enough parochial and subject orientations to keep it within safe boundaries' (Ehrenberg 1999: 205). Whether Putnam's decision to move his focus to Coleman's (1990) reworking of Loury's 'social capital' was a better choice is a point for debate, for social capital quickly became the catch all expression of the new institutional consensus that was forming in Washington to take the place of the previous rather austere version. Civic engagement would continue to occupy an important place in the political science literature, where it would go on to mean many different things from charitable giving, through political advocacy to association membership, community service and artistic expression. But as an umbrella term, critics have argued, it no longer helps the discussion on political, civil, social and moral forms of action and engagement, for simply arguing for more of it in order to strengthen democracy, without being clear what 'it' is, does not help either debate nor programmatic action (Berger 2009).
In 1989, Dreze and Sen were to give a fresh lease to life to public action with the publication of Hunger and Public Action.

By public action we mean not merely the activities of the state, but also social actions taken by members of the public - both 'collaborative' (through civic cooperation) and 'adversarial' (through social criticism and political opposition). The state does, of course, have a major role to play in eradicating famines and in eliminating persistent deprivation, and the various aspects of this role we have tried to discuss fairly extensively in the light of general reasoning and empirical evidence. But the reach of public action goes well beyond the doings of the state, and involves what is done by the public - not merely for the public. We also argue that the nature and effectiveness of the activities of the state can deteriorate very easily in the absence of public vigilance and activism. (Dreze and Sen 1989: viii)

Important in their discussion was the notion of non-homogeneity, of divergent interest groups and the need for a plurality of levers, of complementarities and trade-offs as well as conflicts. Throughout, they reiterate in various moments their concern that public action should not be confused with state action, but included many non-state activities, social and political organisations and as they point out in their conclusions:

Public action is not, of course, just a question of public delivery and state initiative. It is also, in a very big way, a matter of participation by the public in the process of social change ... The collaboration of the public is an indispensable ingredient of public health campaigns, literacy drives, land reforms, famine relief operations, and other endeavours that call for cooperative efforts for their successful completion. On the other hand for the initiation of these endeavours and for the government to act appropriately, adversarial pressures from the public demanding such action can be quite crucial. (Dreze and Sen 1989: 259)

Perhaps because of the main policy focus of the book, as well as the - again - obviousness of the expression, public action seemed to have 
remained an important part of the hunger and livelihood debate, which for many reasons requires a mix of actions at mid-range levels and its important implications for the state-civil society debate were to some extent set aside as the latter went off into other areas of social policy in which social movements - often urban were active as well as non-governmental advocacy and service organisations. The idea of a muddy arena of multiple actors neither fitted into the development agencies concerns with replication and scale, nor did it fit for those whose interests lay in separating state from civil society. If the 1980s had seen the return of Gramsci on to the front shelves of activist bookshops, the 1990s found him replaced by an avalanche of alternative perspectives on strengthening developing democracies that were perhaps less questioning of how things had got to be the way they were and instead, focused on the positive importance of striving for development goals.

One of the problems that this avalanche created was to sweep up a variety of settings and organisational processes into one mot valise. In contrast, as Davies and Hossain (1997: 8) have well argued, on the ground things are far more heterogeneous to the point that formal civil society can be very different to a more informal civil society:

... made up of less defined and less visible rules and alliances based on kinship, caste and gender, which operate within and outside the household. It refers to the more organised elements of communities, easily identifiable by insiders but often invisible to outsiders. The institutional rules of informal civil society are not so frequently converted into organisational "players" as those in civil society'.

While their focus is on livelihoods, their arguments have a wider reach, especially when considering the way in which informal civil society is often marginalised by the state's and formal civil society's actions and how in the absence of more specific and formal public sector it has to become, as it were, a public to and for itself. This would be a theme through many of the cases, not only where different cultures were involved but where social and economic exclusion had forced people very much back onto their own initiatives.
Recently, the expression public action has moved back onto the stage as a result of work in France and in Latin America on new forms of collective action (Laborier and Trom 2003), including the alternative economy and solidarity movements (França Filho et al. 2006). Here it is being used in the wide sense to cover the action of different public institutions and, even more broadly, to include any activity that is being articulated in the public sphere and being carried out in reference to a common good. It includes those activities directly linked to the exercise of public power and those that result from the activities of citizens when showing concerns about collective life. This is a very different use for public action from that over which Lewis (2008) has raised concern; that is, as a support for nongovernmentalism in service provision.

In contrast, our notion of a pluralist action space has also been helpful in looking at the way in which, in different parts of Latin America, work on innovations in local government is pointing to the way that subnational government, and especially local government, is increasingly recognising the importance of citizen presence in many aspects of public services provision.

Similarly, citizen-based mobilisation on public issues is increasingly recognising the importance of moving beyond pressure and engaging actively with government in debating and helping to provide solutions (Cabrera Mendoza 2005; Farah and Spink 2008). Linked in part to what Hirst has called 'negotiated social governance' (2000), new practices of local and mid-range coordination using networks, partnerships and deliberative forums are broadening the way in which action takes place within the very practical horizons of daily life.

These new practices, as we will see in the case studies, are by no means the product of a consensual universe nor are the rationalities present the same. Technical, moral and political arguments fly across each other for very different purposes and outcomes. When co-management becomes co-financing, a very different idea of public goods is enacted as also when sustainable livelihoods requires invading land to provide the minimum of shelter for family life. It is for these reasons that we have returned to the important tensions and conflicts, as well as the heterogeneity that were introduced by Dreze and Sen (1989). However, mindful of the destiny of a 
number of other potential useful expressions which have ended up being 'blister packed' for display in the airport shop of development terminology, we have sought to maintain it in a somewhat contradictory frame by drawing on the notion of hybrid arenas: those spaces that are composed of incongruous elements and drawn from heterogeneous sources. The idea of a hybrid arena is an extension of a discussion in organisational theory that began with the question of hybrid structural forms (Powell 1990) and went on through the hybrid character of social service organisations which bring together state and civil society actors to recognise that organisational arrangements are themselves enacted as part of hybrid arenas; they are somewhat 'spiky' and inexact arrangements, often local in configuration and frequently requiring practical knowledge (Spink and Alves 2008). Bringing the two together, we seek to hold on to the idea of public action as a somewhat chaotic mid-range notion, often contradictory, but like the hybrid arena of which it is an active part something that social actors seem to grapple with for one simple reason: that for all practical purposes, it is the horizon that they have.

\section{Case studies in outline}

In ordering the case studies for publication we have avoided, on the one hand, the simple expedient of alphabetical order or, on the other, of trying to build a complex and logical continuum between processes, structures and actors. The order chosen reflects the discussions between the different case study teams moving from government actors to social actors, from mechanisms to movements in a way that we hope helps to stimulate interest in the different questions they raise.

\subsection{The Philippines}

The Philippines case study documents the progress and conceptual adaptations of coproduction and co-financing approaches in the health sector, pioneered by two NGOs in the province of Palawan in Metro Manila, part of the Baranggay-Bayan Governance Consortium.

The Baranggay-Bayan Governance Consortium is a loose network of NGOs across the Philippines that began engagements with local governments after the People Power revolt and after the opening of institutional opportunities resulting from decentralisation in 1991. The Consortium associates itself with local government officials, social movements and political parties that are interested not only in making use of the so-called democratic spaces but also in the political empowerment of the poor. Members of the Consortium support the empowerment of the poor by utilising different institutional channels opened up by democratisation, by creating community capabilities for increased bargaining power, by supporting local officials who demonstrate a willingness to take risks associated with reform and by working together to identify and change national laws and practices that sustain the exclusionary logic of patronage politics in the country.

The co-production and co-financing approach is a deliberate modification of the Consortium's participatory budget approach that was initiated in the mid-1990s. The older model emphasises an approach whereby municipal level officials are asked to shape their priorities around initiatives that communities are already willing to invest in through their ubiquitous efforts at solving their own problems. This establishes a kind of parity between poor communities and elected politicians. The new approach is based on the realisation that, while the participatory budgeting approach seemed to have important impacts at the lowest level of governance (the Baranggay), where people knew each other, bringing claim-making up to the municipal level brought it face-to-face with long-standing practices of patronage politics, where the formal rules of the game may have provided openings for participation, but in reality public resources continued to be treated like they were the Mayor's own.

\subsection{Peru}

The Peruvian case study looks at spaces for political and social participation in the province of Anta, in the region of Cusco, in the Peruvian Sierra where there is increasing articulation of rural communities, traditionally excluded from the state political dynamics, with urban organisations and local governments. It is a follow-up study of one of Peru's most important experiences in citizen participation in recent years, which took place in the district of Limatambo, in Anta Province where, from intervention from the small farmers and members of communities, there was a significant socialisation of power. 
The success of this experience led to the victory of the local political group in the provincial elections. Among the many different actors involved were political organisations, farm communities, neighbourhood associations, grass roots organisations and NGOs.

This is a region which concentrates the highest levels of poverty and extreme poverty in the country and is traditionally abandoned by the central government's development policies. Anta, with a population that surpasses 50,000 inhabitants, has a malnutrition rate of 46 per cent and more than 30 per cent of the women are illiterate. In addition, it has a high percentage of unsatisfied basic needs; for example, 70 per cent of the population has no access to drainage systems and do not have toilets. In the case of the district of Limatambo the malnutrition rate is 40 per cent, but more than 83 per cent of the population have no access to water. Key therefore is to see how the creation of new spaces for participation are effectively contributing to improve the collective quality of life.

\subsection{India}

The Indian case study focuses on experiences of Communitisation. Communitisation consists of a partnership between the government and the community involving transfer of ownership of public resources and assets, control over service delivery, empowerment, decentralisation, delegation and building capacity of all, with the aim of improving the delivery of public utility systems. Government employees at the service delivery level become accountable to local communities and village committees control government assets not only in terms of the responsibility for maintenance but also for asset improvement. The study looks at how Communitisation has contributed to community empowerment and the improvement of service delivery/poverty reduction in the identified sectors.

Nagas have a strong sense of community and traditional village institutions for selfgovernance have been a part of life in Nagaland. At the same time, its democratic experience has been complex, difficult and painful because of the disparate nature of the tribes and in 45 years of statehood, Nagaland has witnessed significant political instability and violent clashes in 10 out of 11 Districts.
In this context, with widespread cynicism that anything positive can happen in Nagaland and the realisation that improving public services at grass roots level must be a top priority, in 2001, the Nagaland government enacted the Nagaland Communitisation of Public Institutions and Services Act, which institutionalised a process to develop a synergic relationship between the community and the government with the view of creating a sense of ownership of public institutions and better management of limited resources. The law provided for the ownership of public resources and assets and control over service delivery to be transferred directly to the community, including powers of management and supervision over the day-to-day functioning of employees to village committees, and even resource devolution to village committees for payment of employee salaries. The programme initially focused on three sectors: drinking water, education and electricity.

\subsection{China}

In the last 30 years with the open reform policy, China has experienced dramatic changes, such as a polarisation of the social system and segregation, typical of developing countries. Rural migrant workers have become China's largest and most disadvantaged group, working under poor conditions, meager salaries, no medical insurance, no decent work injury compensations, no rights to vote or participate in urban communities, having to pay expensive additional fees to send their children to urban public schools, besides having to struggle for their salaries in arrears and compensation for work injury. Fortunately, in recent years, the rights and social security of rural migrant workers have been greatly improved. A number of government departments, international agencies and civil society organisations have participated in this process, contributing with individual efforts and experiences.

The Chinese case study looks at the construction of anti-exclusion policies for rural migrant labourers in Chengdu, Sichuan, one of the most populated areas in the less-developed western region of the Chinese mainland. A unique feature of interaction between civil society and government in China is that it is only within the framework of political authorisation and guidance from the government that civil society can engage effectively and build mechanisms to 
tackle exclusion and reduce poverty. Compared with other countries, the capability of civil society to promote social or political development is far less than a powerful force in China.

\subsection{Uganda}

Uganda, like many other countries worldwide, has recently embraced a decentralised system of governance, with the main goal of approaching citizens to participatory decision-making processes and improving efficiency and effectiveness of service delivery, as well as fighting poverty and exclusion. Despite a number of important government programmes, policies and structures, a significant number of people in Uganda still remain poor and many still live below the poverty line. There is a high degree of powerlessness and voicelessness that negatively influences the level of organisation for collective action. Citizens' participation appears more during political campaigns and cease immediately after elections and the role of decision-making and participation in government processes is generally taken over by elected leaders. The gap in organisation and capacity by the people has increased the importance of civil society organisations in contributing to local democracy.

The Ugandan case study looks at the role played by local government and civil society organisations in the Walukuba Division, in promoting citizen participation and initiative in local development processes. In particular, it will study the Pressure From Below (PFB) experience, whereby a grass roots organisation has sought to engage with other actors, governmental and non-governmental, as well as influence citizens at the local level to voice their concerns and participate in joint community improvement initiatives. Jinja is the second largest town in Uganda, strategically located near the source of the Nile and formerly the industrial centre of Uganda. Jinja has some of the largest slums in the country, deprived of land tenancy rights, decent accommodation, good sanitation and hygiene, security, adequate health and education facilities.

Among PFB's strategies are: consultative meetings, baseline survey, planning and feedback meetings, audio and written documentation, exposure visits and the use of the media. Others include: keeping pressure through the use of various methods like lobbying, persuasion, confrontation, demand, and sometimes aggressive measures like refusing to attend local meetings organised by the authorities or even listening to the leaders. The use of music, dance and drama is a cheap, entertaining and relevant tool in keeping leaders focused and maintaining interest of participation from the community.

\subsection{South Africa}

The expression of voice is an integral aspect of a developed reflexive delivery system in which community voice operates as an important product to municipalities to meet expressed need. Internationally, there is increasing interest in engaging poor communities and capturing citizen voice in scorecards, and a number of innovations in this direction have taken place in South Africa. The South African case study will analyse the use of scorecards as a step towards improving accountability between citizen and provider, and in particular examines how giving scores has encouraged greater citizen voice/ participation in improving water service delivery in Mbizana, Eastern Cape.

In August 2006, after discussions with a community-based organisation, the Mbizana Legal Advice Genter initiated a project with the aim of training village-based activists to engage their communities in mobilising around their need for improved water and sanitation. The strategy was to cascade training, activities and learning throughout three Wards in the Mbizana municipality. Each trainer trained a community facilitator to spread skills and leadership in each village. Although there was support given to trainers and facilitators from a distance, the activities, including the organisation of the Ward Forums was conducted by the trainers themselves.

All villages were involved in undertaking community assessment and mobilisation activities such as community mapping, timelines, trend-lines, and other exercises well established in participatory appraisal were undertaken as well as innovative tools such as child water access charts, diarrhoea diaries kept by school children, surveys of the needs of people with lower levels of immunity, among others. These exercises culminated in the design of a scorecard on which the villages assessed ten central elements in the regulatory framework for 
water services. These activities leading up to the Ward Forums, whereby each community reported their needs and strategies to the Ward Committees, were to some extent welcomed by the Mbizana municipality, which felt that this helped councillors and officials advocate for better water services from the District Municipality.

\subsection{Mexico}

Gender violence is part of Mexican reality and even more present in the state of Veracruz where, from 2000-05, approximately 1,500 girls and women were murdered. The Mexican government recognises the existence of feminicide as any act of violence against women that may have a sexual, physical, psychological or economic character and may lead to their murder or suicide. This abuse against women ultimately deepens the social exclusion present in all Mexican regions, and is worsened in predominantly indigenous regions, such as the Zongolica Mountain range, where, in addition to the financial, ethnic and gender discriminations, cultural and linguistic differences also contribute to the social exclusion and violence against women.

The Mexican case study will look at the role played by civil society in collaboration with the Veracruz government in implementing legal frameworks that support women's rights and freedom from violence. The research focuses on the relationship between the Veracruz network of citizen organisations (ROCVER) and government actors in the implementation of the Women's Institute in Veracruz, created as a result of both citizen pressure and new legal frameworks. The study pays special attention to the Luz Marina Center, a civil society initiative in the Rafael Delgado municipality in the Zongolica Mountain range established in early 2007 by missionaries from the Immaculate Conception order in partnership with a group of local women. The centre functions as a shelter and legal support centre for indigenous women who suffer from violence, as well as building their capacity as important social actors in the national struggle to end violence against women.

The study looks at how in the Zongolica Mountain range, these experiments in greater articulation between the Women's Institute and other regional organisations have succeeded in changing government policies on violence in a process that has been taking place at a number of different levels and involved civil society organisations in a variety of different areas of activity.

\subsection{Brazil}

The Brazilian case study looks at the experience of Diadema, a small yet overpopulated municipality in the metropolitan region of São Paulo, one of seven municipalities located within the once very industrialised $\mathrm{ABC}$ region in the metropolitan region of São Paulo. In the late 1950s and under the military government, the ABC region became a largely industrial area. The automobile industry thrived in this region and attracted workers from all parts of the country, especially from the north-east, who arrived with the hope of improving their living conditions. The dramatic population increase in the area did not accompany the speed of urban development, generating housing and infrastructure deficits, and consequently forcing people to live in sub-human conditions in the shantytowns that mushroomed in the areas surrounding the industrial parks.

The ABC region is the birthplace of Brazil's Labor Party (PT) led by Lula, Brazil's current president, which confronted the multinationals and the military government in a strike in the 1970 s, with the principal demands of improvement in working conditions and salary increase for the labour union workers. The same people that worked in the industries in the region were also the great majority of the people that built and lived in the shantytowns. As such, the region became a melting pot of social movement leaders, and in the first democratic elections in 1982, Diadema was among the first cities to elect a PT government and has been governed by left-wing parties ever since with intensive citizen participation in policy elaboration and decisions. Not surprisingly, one of the key areas for action was housing and the integration of the shantytowns into the city framework, including land reforms and physical interventions. The case study follows the Diadema municipal housing policy from its conception, focusing on the articulation between different social movements and on the role played by different community activists from the church and the trades unions. 


\section{Notes}

* Many people have played key roles in this collective venture, from the community leaders and government officials in the case studies, through to the many colleagues from the different civil society organisations and research centres that conducted the cases. On behalf of all the case writers, we would like to send them a special thank you and the recognition that if there is any merit to the study, it belongs to them. Other important contributions were made by Florence Raes, who was the LogoLink coordinator at the Pólis Institute during the early stages; John Gaventa of IDS; Joel Rocamora of the Institute for Popular Democracy, who helped to draft out the terms of reference and frame the research questions; as well as Hetifah Sjaifudian Sumarto from the Bandung Trust Advisory Group, Indonesia; Matthew Leighninger of the Deliberative Democracy Consortium, Washington DC; José Carlos Vaz of the Pólis Institute; Jacobus de Visser from the University of the Western Cape; and Hongyun Zhou of the China Centre for Comparative Politics and Economics. All served as external resources for the Bellagio workshop and

\section{References}

Almond, G.A. and Verba, S. (1963) The Civic Culture: Political Attitudes and Democracy in Five Nations, Princeton NJ: Princeton University Press

Berger, B.B. (2009) 'Political Theory, Political Science and the End of Civic Engagement', Perspectives on Politics 7.2: 335-50

Cabrera Mendoza, E. (2005) Acción Publica e Desarollo Local, Mexico DF: Fondo de Gultura Economica

Coleman, J.S. (1990) Foundations of Social Theory, Cambridge MA: Harvard University Press

Davies, S. and Hossain, N. (1997) Livelihood Adaptation, Public Action and Civil Society: A Review of the Literature, IDS Working Paper 57, Brighton: IDS

Dreze, J. and Sen, A. (1989) Hunger and Public Action, London: Clarendon Press

Ehrenberg, J. (1999) Civil Society: The Critical History of an Idea, New York: New York University Press

Farah, M.F.S. and Spink, P. (2008) 'Subnational Government Innovation in a Comparative Perspective: Brazil', in Sandford Borins (ed.), provided many important comments and pointers to the work in hand. Finally our thanks also go to the Ford Foundation and the Rockefeller Foundation for the grants and the encouragement to carry the work through and the staff of the IDS Bulletin for their support and comprehension of the difficult process of preparing texts for publication from different parts of the world over many different time zones.

1 LogoLink is a global network of practitioners from civil society organisations, research institutions and governments working to deepen democracy through greater citizen participation in local governance, improving relationships between those who govern and those who are governed. It encourages learning from field-based innovations and focuses on expressions of democracy that contribute to social justice. It receives support from the Ford Foundation as well as a number of other agencies. The current study was greatly benefited by support from the Rockefeller Foundation, which enabled the research teams to meet at the Bellagio Center, Italy to debate the preliminary versions of the case studies and possible conclusions.

Innovations in Government: Research, Recognition and Replication, Washington DC: Brookings Institution: 71-92

Ferguson, A. (1767; 1995) An Essay on the History of Civil Society, Cambridge: Cambridge

University Press

França Filho, G.G.; Laville, J-L.; Medeiros, A. and Magnen, J.P. (eds) (2006) Ação Pública e Economia Solidária: Uma Perspectiva Internacional, Porto Alegre, Brazil: Editora da Universidade Federal de Rio Grande do Sul

Hirschman, A.O. (1982) Shifting Involvements: Private Interests and Public Action, New Jersey: Princeton University Press

Hirst, P. (2000) 'Democracy and Governance', in Jon Pierre (ed.), Debating Governance: Authority, Steering and Democracy, Oxford: Oxford University Press

Laborier, P. and Trom, D. (eds) (2003) Historicités de l'Action Publiue, Groupe de Sociologie Politique e Morale, Centre Universitaire de Recherches Administratives e Politiques de Picardie, Paris: Les Presses Universitaires de France (PUF) Lewis, D. (2008) 'Nongovernmentalism and the Reorganization of Public Action', in Sadhi Dar 
and Bill Cooke (eds), The New Development Management, London: Zed Books: 41-55

Nelson, P.J. and Dorsey, E. (2008) New Rights Advocacy: Changing Strategies of Development and Human Rights NGOs, Washington DC:

Georgetown University Press

Powell, W.W. (1990) 'Neither Market nor Hierarchy: Networks Forms of Organization', Research in Organizational Behavior 12.2: 295-336

Putnam, R.D. (1988) 'Institutional Performance and Political Culture: Some Puzzles About the Power of the Past', Governance 1.3: 221-42
Spink, P. and Alves, M.A. (2008) 'Hybrid Arenas and the Dilemmas of Public Action: Looking for a Different Bottom Line', II Colloquium of the Latin American European Meeting on Organizational Studies, Rio de Janeiro, 15-18 April, unpublished paper 